

\title{
Marcadores discursivos focalizadores com "bem" sob a perspectiva da Linguística Funcional Centrada no Uso
}

\author{
Patrícia Fabiane Amaral da Cunha Lacerda ${ }^{1}$ \\ Gustavo Ribeiro Patrício Barbosa ${ }^{2}$
}

\begin{abstract}
Resumo: Este trabalho tem como objetivo fundamental propor uma rede construcional constituída por marcadores discursivos focalizadores formados por verbos de percepção cognitiva no imperativo na segunda pessoa do discurso e pelo advérbio focalizador bem, como, por exemplo, "olha bem", "veja bem" e "repara bem". A fim de cumprir o objetivo proposto, baseamo-nos, do ponto de vista teórico, na Linguística Funcional Centrada no Uso (BYBEE, 2010; MARTELOTTA, 2011; FURTADO DA CUNHA et al., 2013; TRAUGOTT; TROUSDALE, 2013; ROSÁRIO; OLIVEIRA, 2016; BISPO; SILVA, 2016), abordagem que concebe a língua como um inventário de construções organizadas em rede. Também para o cumprimento do objetivo proposto, realizamos uma análise sincrônica de dados a partir de um corpus escrito sincrônico atual, cujas amostras representam os anos de 2008, 2011, 2014 e 2017. Para o tratamento dos dados, adotamos, do ponto de vista metodológico, o equacionamento entre a análise qualitativa dos dados e o cálculo da frequência de uso (CUNHA LACERDA, 2016). Como resultado mais proeminente, a análise realizada aponta que as construções identificadas, cuja forma mais genérica é [verbo imperativo + bem], apresentam diferentes funções, entre as quais se destacam a chamada de atenção do interlocutor pelo locutor e a focalização de um elemento da sequência discursiva.
\end{abstract}

Palavras-chave: Linguística Funcional Centrada no Uso. Construcionalização gramatical. Focalização. Marcadores discursivos focalizadores. Marcadores discursivos com "bem".

\section{Introdução}

Este trabalho, apoiando-se nos pressupostos teóricos da Linguística Funcional Centrada no Uso (BYBEE, 2010; MARTELOTTA, 2011; FURTADO DA CUNHA et al., 2013; TRAUGOTT; TROUSDALE, 2013; ROSÁRIO; OLIVEIRA, 2016; BISPO; SILVA,

\footnotetext{
${ }^{1}$ Pós-doutora em Linguística pela Universidade Federal de Minas Gerais (2009), doutora em Linguística pela Universidade Federal de Minas Gerais (2007), mestre em Linguística pela Universidade Federal de Juiz de Fora (2003). Professora Associada da Faculdade de Letras da Universidade Federal de Juiz de Fora, atuando no Departamento de Letras Estrangeiras Modernas e no Programa de Pós-graduação em Linguística. Pesquisadora do Grupo de Estudos "Discurso \& Gramática"; e coordenadora do NUPACT/UFJF. Minas Gerais, Brasil. Email: patricia.cunha@ufjf.edu.br. ORCID iD: 0000-0002-0970-224X

${ }^{2}$ Doutorando em Linguística pela Universidade Federal de Juiz de Fora, atuando na área de Linguística e cognição, com foco na Linguística Funcional Centrada no Uso (LFCU) e na Abordagem Construcional da Mudança. Atua como Analista de Instrumento de Avaliação na Fundação Centro de Políticas Públicas e Avaliação da Educação (Fundação CAEd/UFJF) da Faculdade de Educação da Universidade Federal de Juiz de Fora. Minas Gerais, Brasil. E-mail: gustavo.grpb@gmail.com. ORCID iD: 0000-0002-0598-9810
} 
2016), tem como objetivo fundamental propor uma rede construcional constituída por marcadores discursivos focalizadores formados por verbos de percepção cognitiva no imperativo na segunda pessoa do discurso e pelo advérbio focalizador bem, como, por exemplo: "olha bem", "veja bem" e "repara bem". Esses marcadores discursivos têm como objetivo a chamada de atenção por parte do locutor a seu(s) interlocutor(es). A seguir, apresentamos duas ocorrências que caracterizam o objeto de análise deste trabalho:

(1) “A maquiagem mineral é ótima para peles sensíveis por ter uma formulação mais 'natural' o que a torna hipoalergênica. Veja bem, isso NÃO significa que você não terá alergia, significa que o risco de uma reação alérgica é menor.”. (Corpus escrito blogs).

(2) “A novela é de 1995. Talvez você, leitor do Gigablog, não fosse nascido (ou era bebê demais para guardar lembranças). Vamos tentar refrescar sua memória: um dos protagonistas era o cigano Igor, papel do ator Ricardo Macchi, que tinha falas um tanto lacônicas para expressar seu amor. "Eu te amo, Daaara" era a mais famosa delas. Pois bem, por que raios estou falando disso aqui no blog? Repare bem na abertura da novela Explode Coração (não dá para negar que Hans Donner bebe de uma fonte inesgotável de criatividade bizarra)" (Corpus escrito blogs).

Os exemplos acima apresentam os marcadores discursivos focalizadores em destaque em ocorrências reais de uso, nas quais podemos perceber que a função em comum é a chamada de atenção para um elemento do discurso por parte do locutor em relação a seu interlocutor. Nas ocorrências (1) e (2), os marcadores utilizados são, respectivamente, "veja bem" e "repare bem", em que o advérbio "bem" apresenta foco avaliativo, indicando um pedido de análise feito pelo locutor a seu interlocutor com foco avaliativo em relação a uma informação do discurso, pois o locutor deseja que seu interlocutor avalie uma informação sob o mesmo ponto de vista, de modo a tentar convencê-lo de tal posição.

Vale destacar aqui que, embora os marcadores discursivos já tenham sido amplamente explorados nos estudos linguísticos (SCHIFFRIN, 1987; MARCUSCHI, 1989; BRINTON, 1996; ROST-SNICHELOTTO, 2008; entre outros), ainda há poucos estudos que visam à análise desse objeto sob um viés construcional, principalmente sob a abordagem da construcionalização gramatical (TRAUGOTT; TROUSDALE, 2013). Nesse sentido, uma de nossas hipóteses é a de que os significados do verbo e dos advérbios têm impacto na função de cada marcador; por outro lado, a partir de características em comum, é possível agrupar os 


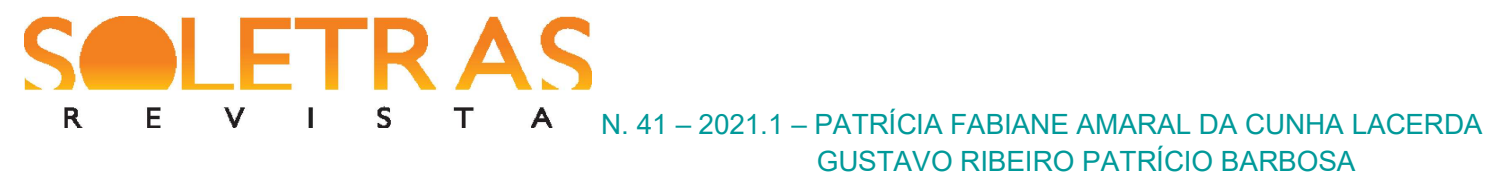

marcadores estudados em uma rede taxonômica hierarquicamente organizada, cujo nível mais alto configura uma abstração com base nas similaridades identificadas.

A fim de cumprir o objetivo proposto neste trabalho, contamos, do ponto de vista metodológico, com um corpus escrito sincrônico atual, cujas amostras representam os anos de 2008, 2011, 2014 e 2017 e cujos textos foram retirados de blogs de diferentes temáticas, apresentando uma modalidade mais informal da língua (OLIVEIRA, 2012, 2016; MARTINS DALL'ORTO, 2018). A análise foi feita a partir do método misto - que equaciona a análise quantitativa e a qualitativa -, já que, como destaca Cunha Lacerda (2016), o método misto pode contribuir substancialmente para a compreensão de como as inovações que emergem no fluxo da interação se fazem regulares na língua.

Nesse sentido, a fim de efetivamente propor uma rede construcional constituída por marcadores discursivos focalizadores formados por verbos de percepção cognitiva no imperativo na segunda pessoa do discurso e pelo advérbio focalizador bem, este trabalho organiza-se da seguinte forma: em um primeiro momento, discutimos os pressupostos fundamentais da Linguística Funcional Centrada no Uso, tratando, de modo particular, das proposições de Traugott e Trousdale (2013) acerca da construcionalização gramatical; em um segundo momento, tratamos da noção de focalização do ponto de vista teórico e definimos marcadores discursivos; já em um terceiro momento, apresentamos os procedimentos metodológicos a partir dos quais se constitui a análise; em um quarto momento, tratamos efetivamente da análise dos dados e da proposta de rede construcional; por fim, nas considerações finais, sistematizamos as conclusões a que chegamos a partir da realização do trabalho.

\section{A construcionalização gramatical no âmbito da Linguística Funcional Centrada no Uso}

A Linguística Funcional Centrada no Uso compreende a denominação adotada, mais recentemente, para se referir às pesquisas funcionalistas que coadunam princípios formulados no âmbito do funcionalismo de vertente norte-americana e da Gramática de Construções (BYBEE, 2010; TRAUGOTT; TROUSDALE, 2013; FURTADO DA CUNHA et al., 2013; ROSÁRIO; OLIVEIRA, 2016; BISPO; SILVA, 2016). 


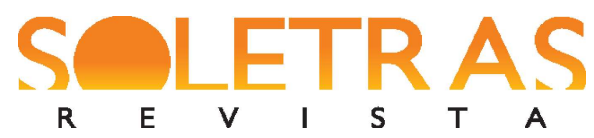

N. 41 - 2021.1 - PATRÍCIA FABIANE AMARAL DA CUNHA LACERDA GUSTAVO RIBEIRO PATRÍCIO BARBOSA

Na contemporaneidade, a pesquisa funcionalista que se baseia na centralidade do papel do contexto e que se pauta no pressuposto de que a estrutura linguística deriva de processos cognitivos gerais tem recebido a denominação de Usage Based Linguistics - Linguística Centrada no Uso - ou Cognitive-Functional Linguistics - Linguística Cognitivo-Funcional (BYBEE, 2010; TRAUGOTT; TROUSDALE, 2013). De modo bastante particular, essa vertente mais contemporânea do Funcionalismo tem sido denominada, no Brasil, de Linguística Funcional Centrada no Uso - ou LFCU - a fim de que, primordialmente, seja demarcada a identidade funcionalista em uma Linguística que seja centrada no uso.

Nesse contexto, para a Linguística Funcional Centrada no Uso - ou LFCU - há uma relação estrita e indissociável entre os aspectos formais e os aspectos funcionais de uma construção. Enquanto, no funcionalismo clássico - que, nos termos de Rosário e Oliveira (2016), compreende os estudos pioneiros da vertente norte-americana - assume-se a correlação função > forma, na Linguística Funcional Centrada no Uso, assume-se a bidirecionalidade função $<>$ forma. Nesse sentido, forma e função assumem igual estatuto e igual importância (OLIVEIRA; ARENA, 2016).

Nesse sentido, a Linguística Funcional Centrada no Uso - LFCU (ou versão contemporânea do funcionalismo) - constitui-se a partir de noções e princípios basilares da Gramática de Construções, tomando como referência os modelos construcionistas: i) que assumem o compromisso de explicar a estrutura linguística a partir de processos cognitivos gerais; e ii) que são, nesse sentido, identificados epistemologicamente com a Linguística Cognitiva e também com a Linguística Funcional.

A Gramática das Construções (GrC), em todos os seus modelos, pode ser considerada uma teoria de gramática em sintonia com os pressupostos sociocognitivos enfeixados pela Linguística Cognitiva (LAKOFF; JOHNSON, 1980; FILLMORE, 1982; FILLMORE et al., 2003; CROFT; CRUSE, 2004). Formulada no contexto da Linguística Cognitiva, a Gramática de Construções defende o postulado de que, de uma perspectiva sincrônica, a língua é constituída de pareamentos forma-significado - as chamadas construções -, organizados em rede (GOLDBERG, 1995, 2006; CROFT, 2001). E, mais recentemente, a partir de Goldberg (2016), compreende-se que as construções da língua constituem pareamentos forma-função.

Assumir os pressupostos da Gramática de Construções quer dizer que o conhecimento linguístico dos falantes consiste em uma rede de construções. Nesse sentido, a construção é a 


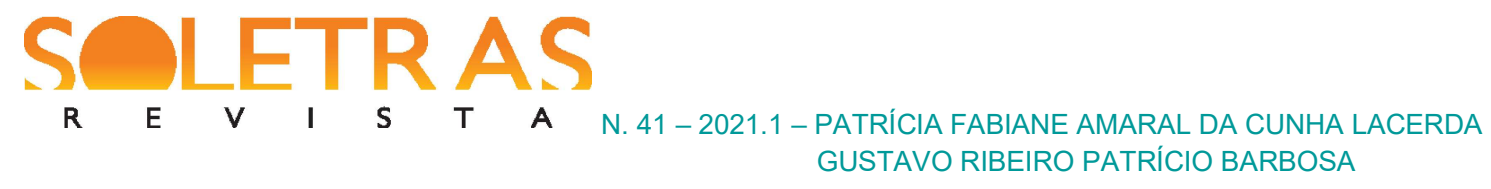

unidade básica da língua (GOLDBERG, 1995, 2006). E a língua, como outros sistemas cognitivos, compreende uma rede de nós ligados por elos, e as associações entre alguns desses nós tomam a forma de hierarquias de herança (LANGACKER, 1987).

Nesse contexto, a publicação da obra Constructionalization and Constructional Changes, por Traugott e Trousdale, em 2013, traz importantes contribuições para o tratamento sistemático de processos de mudança linguística no que se refere tanto à gramática como ao léxico. Ao proporem um modelo teórico para a compreensão da mudança, Traugott e Trousdale (2013) assumem a centralidade da noção de rede construcional e defendem que a língua, tanto no que se refere à gramática quanto ao léxico, constitui-se a partir de redes taxonômicas de construções, as quais seriam hierarquicamente constituídas e organizadas.

Fundamentando-se na proposta da Radical Construction Grammar (CROFT, 2001), os autores partem do princípio de que nenhuma construção é instanciada de modo isolado, uma vez que a língua seria constituída por redes construcionais hierarquicamente organizadas, em que cada construção representa um nó específico. Traugott e Trousdale (2013), ao defenderem que as construções da língua se organizam em redes taxonômicas, operam com a distinção entre quatro níveis, a saber: construto, microconstrução, subesquema e esquema.

Os construtos compreendem as ocorrências atestadas empiricamente, caracterizandose como sendo o locus da mudança. Desse modo, estão relacionados à frequência token, que caracteriza o número de ocorrências de determinada construção (BYBEE, 2003). Já as microconstruções compreendem as construções individuais propriamente ditas, que se realizam a partir de um pareamento entre forma e significado e já se encontram convencionalizadas e produtivas na língua. Por sua vez, os subesquemas envolvem o conjunto de similaridades que é observável entre microconstruções diversas. E os esquemas possuem uma natureza altamente abstrata e esquemática, compreendendo as construções mais genéricas da rede e abarcando as estruturas complexas com possibilidades diversas de preenchimento (slots).

Além disso, os autores propõem um modelo que compreende a mudança linguística a partir de duas diferentes dimensões, as quais eles intitulam de mudança construcional e construcionalização. Enquanto a construcionalização envolve a emergência de novas construções na língua a partir do pareamento entre forma e significado, a mudança construcional está relacionada à dimensão interna da construção, uma vez que são afetados os 


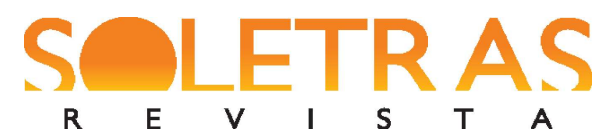

$\begin{array}{llllllll}\mathbf{R} & \mathbf{E} & \mathbf{V} & \mathbf{I} & \mathbf{S} & \mathbf{T} & \mathbf{A} & \mathrm{N} .41-2021.1 \text { - PATRÍCIA FABIANE AMARAL DA CUNHA LACERDA }\end{array}$

GUSTAVO RIBEIRO PATRÍCIO BARBOSA

subcomponentes de uma construção já existente, sejam eles relacionados à forma (subcomponentes de natureza fonética, morfológica e sintática) ou ao significado (subcomponentes de natureza semântica, pragmática e discursiva). E, como ainda assumem Traugott e Trousdale (2013), a diferença entre construções lexicais e construções gramaticais reside no grau de complexidade interna de cada uma delas (GOLDBERG,1995), de modo que a fronteira entre elas é difusa.

Com base nos pressupostos da Linguística Funcional Centrada no Uso e, de modo mais pontual, na noção de construcionalização gramatical (TRAUGOTT; TROUSDALE, 2013), assumimos, neste trabalho, que os marcadores discursivos focalizadores constituem casos de construcionalização gramatical, em que se observa a chamada de atenção por parte do locutor a seu(s) interlocutor(es).

\section{Focalização e marcadores discursivos : uma breve discussão}

No âmbito de sua gramática funcional, Dik (1989) apresenta a linguagem como um instrumento de interação verbal, a qual é definida como uma atividade estruturada, regida por normas e convenções, sendo uma atividade cooperativa, na qual dois falantes cooperam para sua realização. Sob essa perspectiva, o autor apresenta o conceito de foco e focalização, afirmando que a função pragmática do foco pertence à função focalizadora do discurso, isto é, a informação focalizada é aquela mais proeminente e relativamente mais importante no conjunto comunicativo. Em outras palavras, o foco é motivado pela necessidade de contraste de um elemento em relação a outros no enunciado. A partir disso, o autor postula que a função de foco pode se manifestar por meio dos seguintes recursos focalizadores: i) proeminência prosódica; ii) ordem especial de constituinte; iii) marcadores especiais de foco; e iv) construções especiais de foco. A partir do que postula Dik (1989), a delimitação do foco ocorre a partir de operadores do discurso, os quais, levando-se em conta as construções analisadas nesta pesquisa, podem ser o modo verbal (imperativo) e os advérbios, que, como veremos na seção dedicada à análise, apresentam claras noções de escopo que dialogam com as questões postas pelo autor em relação ao foco e à focalização.

$\mathrm{O}$ uso do modo imperativo nos marcadores discursivos analisados nesta pesquisa 


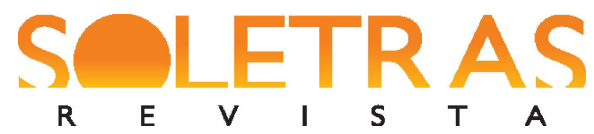

N. 41 - 2021.1 - PATRÍCIA FABIANE AMARAL DA CUNHA LACERDA GUSTAVO RIBEIRO PATRÍCIO BARBOSA

também indica que há uma relação com o tipo de focalização, principalmente no que se refere ao foco dado ao interlocutor, uma vez que este é chamado a participar do discurso por meio do marcador. Travaglia (2006), ao tratar do modo imperativo, afirma que as formas verbais essencialmente marcam modalidade, além de marcarem um enunciado no tempo presente que visa a uma ação em um tempo futuro. Sob essa perspectiva, vale ressaltar que Palmer (1986), em sua obra "Mood and Modality", já trata exatamente dessas questões destacadas por Travaglia (2006): o modo e a modalidade verbal.

Palmer (1986) define o conceito de modo verbal como um sistema basicamente e prototipicamente binário, no qual as proposições têm tipicamente o caráter realis ou irrealis. Além disso, para o autor, o modo e o sistema modal são maneiras com que as línguas geralmente lidam gramaticalmente com a modalidade, pois essa se configura como o status da proposição que descreve o evento (PALMER, 1986), como uma categoria que está rigorosamente associada ao aspecto e ao tempo de uma proposição, mas que nem sempre está marcada no complexo verbal.

O conceito de modo, então, assim como a modalidade, tem relação com o evento e a proposição em que aparece; por isso, também se relaciona aos conceitos de realis e irrealis. Palmer (1986) também define esses conceitos de forma binária: realis diz respeito ao que é factual e real, ao passo que irrealis diz respeito ao oposto, ao que não é factual e o que é irreal. Portanto, por se tratar de um pedido, uma solicitação etc. e caracterizar algo que não depende do locutor, o imperativo se encaixa no conceito de irrealis. O autor também relaciona o imperativo à modalidade deôntica, por seu caráter claramente diretivo, por indicar um comando e também pelo fato de caracterizar eventos possíveis no futuro.

Outro aspecto relevante sobre o modo imperativo é que, normalmente, ele não ocorre em orações subordinadas ou em perguntas por ser performativo. Consequentemente, os marcadores discursivos analisados nesta pesquisa também ocorrem de forma independente de outra oração, no que tange à sintaxe e à sua forma, contudo, isso não impede que haja marcadores que desencadeiem uma oração subordinada, uma vez que o modo imperativo configura uma oração independente que pode ou não requerer uma oração subordinada. No que tange ao foco, consideramos que, por incluir o interlocutor no discurso, ao chamar a sua atenção, o locutor faz uso do modo imperativo com consciência de sua força semântica, a qual, como explicitou Palmer (1986), está associada à modalidade deôntica, à modalidade da 


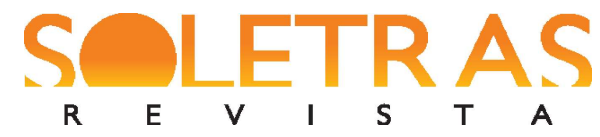

N. 41 - 2021.1 - PATRÍCIA FABIANE AMARAL DA CUNHA LACERDA GUSTAVO RIBEIRO PATRÍCIO BARBOSA

necessidade, da ordem, da obrigação, da volição e da permissão.

Nesse sentido, como assumimos neste trabalho, os marcadores discursivos analisados atuam como elementos focalizadores tanto no que tange ao modo imperativo dos verbos, quanto ao escopo do advérbio bem, que se liga aos verbos de percepção para formar as construções analisadas. Sob essa perspectiva, também delimitamos, nesta seção, a concepção de marcador discursivo assumida neste trabalho.

Em termos gerais, os marcadores discursivos são entendidos como unidades do discurso que sequenciam um tópico conversacional com a finalidade de o locutor chamar a atenção de seu interlocutor para o tópico a ser discutido. Os marcadores discursivos podem ser, então, expressões da fala (como “ei”, “ah”, “oh” etc.), verbos, conjunções, advérbios e, até mesmo, combinações entre mais de um desses elementos, como é o caso dos marcadores discursivos analisados nesta pesquisa.

Marcuschi (1989) trata dos marcadores discursivos sob a nomenclatura de marcadores conversacionais (MCs). Nesse sentido, o autor afirma que "elementos de todas as classes gramaticais e formas sintáticas podem em princípio funcionar como MCs" (MARCUSCHI, 1989, p. 290), o que significa, então, que não se identifica um marcador pela classe gramatical, mas sim pela função que aquela forma passa a adquirir no discurso. $\mathrm{O}$ autor, então, os classifica como i) MC simples: realizados apenas com um só lexema, tais como as interjeições, advérbios, verbos etc.; ii) MC composto: os que têm caráter sintagmático, com tendência a pouca variação morfológica; iii) MC oracional: que se realiza como pequenas orações, podendo ocorrer em diversos tempos e modos verbais, englobando os marcadores de caráter estritamente semântico e pragmático, como a repetição de frases curtas; e iv) MC prosódico: que se realiza apenas com recursos prosódico, como entonação, pausa, hesitação etc..

Como este trabalho visa a analisar a construcionalização gramatical de marcadores discursivos formados por um verbo no modo imperativo associado a um advérbio, podemos entender que, conforme as definições de Marcuschi (1989), essas construções configuram-se como marcadores compostos, pois todos eles apresentam funções sintagmáticas e tendem a pouca variação morfológica, já que, nos termos de Bybbe (2010), eles constituem chunkings, ou seja, unidades de processamento linguístico. 


\section{Procedimentos metodológicos}

Nesta seção, apresentamos os procedimentos metodológicos adotados nesta pesquisa. Na subseção 4.1, tratamos da descrição do corpus sincrônico sob análise. Posteriormente, na subseção 4.2, abordamos o equacionamento entre a análise qualitativa e o cálculo da frequência de uso na investigação das ocorrências (CUNHA LACERDA, 2016).

\section{A constituição do corpus}

Como este trabalho visa à análise de marcadores discursivos que apresentam formas originadas a partir dos padrões fluidos de uso da língua, cujas motivações podem ser cognitivas e discursivas, uma análise de dados sincrônicos torna-se viável e produtiva para esta pesquisa.

O corpus escolhido para a análise apresentada nesta pesquisa consiste de textos escritos retirados de blogs disponíveis na internet. Esses blogs apresentam temáticas variadas (estilo de vida, maquiagem, viagem etc.), e a escolha desse gênero textual, como defendem Oliveira (2012, 2016) e Martins Dall'Orto (2018), deve-se ao grau de menor formalidade presente nesses textos, já que seriam caracterizados por um menor grau de monitoramento da escrita com o objetivo de se aproximarem de seu público-alvo e de se tornarem mais acessíveis, apresentando maior ocorrência de construções que estão em processo de mudança na gramática e no léxico da língua. Com isso, construções de marcadores discursivos tenderiam a ocorrer com frequência considerável em textos como esses, uma vez que se caracterizam, dentre outras funções - como a chamada de atenção -, como conectores dos elementos e passagens textuais.

Neste trabalho, realizamos uma análise sincrônica de dados a partir de um corpus escrito sincrônico atual, cujas amostras representam os anos de 2008, 2011, 2014 e 2017. Nesse sentido, vale destacar que as amostras referentes aos anos de 2008, 2011 e 2014 foram compiladas por Oliveira (2012, 2016) e Martins Dall'Orto (2018). Como assumimos neste trabalho, por se encontrarem muito próximos os anos que compõem as amostras, 
consideramos que, de modo geral, elas representam, de forma bastante correlata, o objeto de estudo analisado.

Cada amostra analisada é composta de trezentas mil palavras, totalizando um milhão e duzentas mil palavras, como apresentado na tabela abaixo.

Tabela 1 - Constituição do corpus

\begin{tabular}{|l|l|l|l|}
\hline \multicolumn{2}{|c|}{ Corpus } \\
\hline Origem & Nível de formalidade & \multicolumn{1}{c|}{ Amostra } & $\begin{array}{c}\text { Total de número } \\
\text { de palavras analisadas }\end{array}$ \\
\hline$B \log s$ & Informal & 2008 & 300.000 \\
\hline$B \log s$ & Informal & 2011 & 300.000 \\
\hline$B \log s$ & Informal & 2014 & 300.000 \\
\hline$B \log s$ & Informal & 2017 & 300.000 \\
\hline \multicolumn{1}{|c|}{ Total } & 1.200 .000 \\
\hline
\end{tabular}

Os dados retirados desse grande corpus, divididos por marcador discursivo e suas respectivas frequências de uso, estão apresentados na Tabela 2:

Tabela 2 - Número de ocorrências dos marcadores discursivos com bem

\begin{tabular}{|l|l|l|l|}
\hline \multicolumn{5}{|c|}{ Corpus Blogs - 2008, 2011, 2014 e 2017} \\
\hline $\begin{array}{l}\text { Marcador } \\
\text { discursivo }\end{array}$ & Veja bem & Repara bem & Olha bem \\
\hline n. $^{\text { }}$ & 16 & 2 & 1 \\
\hline \multicolumn{4}{|c|}{ Total: 19} \\
\hline
\end{tabular}

Conforme os dados apresentados na Tabela 2, podemos concluir que temos um marcador prototípico, o qual é mais produtivo: veja bem. Outro aspecto importante a ser ressaltado a partir dos dados dessas tabelas é que os marcadores destacados podem estar conjugados em relação aos pronomes $t u$, você e você $s^{3}$. Contudo, consideramos que as ocorrências devem ser entendidas como formas diferentes de se dirigir ao interlocutor, representando, até mesmo, diferença de registro. Entretanto, como se configuram como o mesmo verbo, não há necessidade de separá-los para análise e contabilização.

\footnotetext{
${ }^{3}$ Destacamos aqui que estas três possibilidades ocorrem em virtude da variação das formas imperativas que caracterizam o português brasileiro.
} 


\section{O método misto de análise}

Este trabalho, ao propor organizar em rede as construções de marcadores discursivos focalizadores, como "olha bem" e "veja bem", assume, do ponto de vista metodológico, o método misto de análise.

Como destaca Cunha Lacerda (2016), o método misto é importante para a análise de dados de pesquisas sobre mudança linguística por apontar evidências empíricas sobre os níveis esquemáticos de uma rede construcional. Para autora, o método misto está pautado no equacionamento entre as metodologias qualitativa e quantitativa, que, aplicadas à análise, relacionam-se à frequência token e à frequência type. Segundo Bybee (2003, 2007), enquanto a frequência token diz respeito à frequência de ocorrência de uma unidade - geralmente uma palavra ou morfema - em um corpus de análise, a frequência type relaciona-se à frequência de um padrão particular. Nesse sentido, a partir de Bybee (2003, 2007), Traugott e Trousdale (2013) consideram que a frequência token corresponde à extensibilidade de uso de determinado construto, isto é, ao número de vezes que um mesmo padrão aparece atestado empiricamente. Por sua vez, a frequência type, de acordo com os autores, está relacionada à extensibilidade de uso de construções de natureza relacional e esquemática, isto é, ao número de diferentes padrões construcionais que determinada construção mais esquemática apresenta e sanciona.

Schiffrin (1987) também defende o método misto de análise ao julgar que o equacionamento dos métodos quantitativo e qualitativo permite ao pesquisador a obtenção de mais ocorrências e uma análise adequada dos padrões que podem estar sendo formados. E essa análise, segundo a autora, pode ser baseada em uma descrição prévia, porém deve ganhar novas elaborações e adequações de acordo com o que os dados mostram.

Embora seu trabalho não se dedique pontualmente à proposição de uma metodologia no âmbito da abordagem construcional da mudança, Traugott e Trousdale (2013) também sinalizam que o método misto é adequado para a análise de trabalhos no âmbito da mudança linguística. Para os autores, esse método de análise de dados permite que o pesquisador estabeleça uma relação entre frequência e entrincheiramento das construções, além de 
possibilitar a verificação do grau de abstração que um dado grupo de construções pode apresentar para uma comunidade de fala. Os autores também afirmam que a propriedade da esquematicidade está relacionada ao aumento de produtividade e à generalidade semântica. Segundo eles, o método quantitativo de análise pode contribuir para verificar a natureza do entrincheiramento das construções e dos esquemas, além de fornecer pistas sobre prototipicidade de uma microconstrução, já que o chunking é um importante fator que pode demonstrar como uma microconstrução se desenvolve ao longo do tempo, desde que analisado a partir de um corpus.

No que se refere ainda à metodologia, vale destacar que, para o delineamento dos níveis esquemáticos que compõem a rede construcional proposta no trabalho, assume-se uma análise bottom-up, pautada na consideração inicial dos construtos e em sua posterior separação por padrões microconstrucionais a fim de agrupá-los em subesquemas e em esquema.

\section{Análise de dados}

Nesta seção, apresentamos a análise dos dados realizada para esta pesquisa referente aos marcadores discursivos focalizadores com bem, como, por exemplo, "olha bem", "veja bem" e "repara bem". Desse modo, os objetivos desta análise são: a) descrever os pareamentos forma-função de marcadores discursivos focalizadores formados por verbos de percepção cognitiva no imperativo e pelo advérbio bem, tendo em vista a intenção de agrupálos em rede, demarcando seu caráter focalizador e seus respectivos objetos de focalização; b) propor uma rede construcional desses marcadores que abranja os padrões de todas as construções e que apresente os níveis esquema, subesquema e microconstrução.

Nesse sentido, organizaremos a análise da seguinte maneira: i) apresentaremos a descrição do esquema; ii) apresentaremos cada subesquema com suas respectivas microconstruções; iii) sistematizaremos uma proposta de rede construcional para os marcadores discursivos analisados neste trabalho. 


\section{O esquema}

O objeto de análise deste trabalho - marcadores discursivos focalizadores com bem - é composto, no nível mais genérico da rede - o esquema -, pelas características referentes à sua forma e à sua função, descritas no quadro abaixo.

\begin{tabular}{|l|l|}
\hline \multicolumn{2}{|c|}{ Esquema } \\
\hline Forma & $\begin{array}{l}\text { [verbo* no modo imperativo em na segunda pessoa do discurso + bem } \\
\text { *em que se encaixam apenas os verbos de percepção cognitiva, tais como } \\
\text { "olhar", "ver" e "reparar". }\end{array}$ \\
\hline Função & $\begin{array}{l}\text { Chamada de atenção a um pedido de análise, do locutor ao interlocutor, } \\
\text { com foco avaliativo a uma informação do discurso. }\end{array}$ \\
\hline
\end{tabular}

Quadro 1 - Descrição do esquema da rede

A representação da forma, no esquema, que abrange as características de suas respectivas microconstruções, é representada por [verbo no modo imperativo na segunda pessoa do discurso + bem], em que, na posição de verbo, encaixam-se apenas os verbos de percepção cognitiva - tais como "olhar" e "ver" -, no modo imperativo, na segunda pessoa do discurso, a qual é representada pelos pronomes "tu", "você" e "vocês". Juntamente com o verbo, temos o advérbio bem, que apresenta escopo avaliativo em relação ao verbo e à informação focalizada. Já a função deste subesquema é descrita como uma chamada de atenção em relação a um pedido de análise, do locutor ao interlocutor, com foco avaliativo para uma informação do discurso. Isto é, os marcadores discursivos que fazem parte da hierarquia deste subesquema apresentam essa função em comum, que diz respeito a um pedido de análise feito pelo locutor a seu interlocutor com foco avaliativo em relação a uma informação do discurso, pois o locutor deseja que seu interlocutor avalie uma informação sob o mesmo ponto de vista, de modo a tentar convencê-lo de tal posição.

Nesse caso, o foco avaliativo incide sobre dois pontos: o verbo e a informação focalizada. Primeiramente, devemos ter em mente que os advérbios, como destaca Neves (2000), constituem uma palavra periférica que funciona, em um sintagma, como satélite de um núcleo - ou constituinte. E esse núcleo - ou constituinte - pode ser, dependendo das 
subclasses do advérbio, um verbo, um adjetivo (ou sintagma com valor adjetival), um advérbio (ou sintagma com valor adverbial), um numeral, um substantivo ou um pronome. No caso particular deste trabalho, o advérbio bem, sendo um advérbio de modo, tem a função de modificar a maneira como o interlocutor deve analisar a informação, mudando o sentido do verbo. Por outro lado, em relação à informação focalizada, esta deve ser analisada da maneira solicitada pelo locutor. Desse modo, o foco avaliativo recai sobre essa informação. E essa informação focalizada, conforme mostraremos mais adiante, pode ocorrer por meio de uma oração encaixada, de uma oração coordenada, de um sintagma nominal, de um sintagma preposicional, entre outros. A forma como ela é apresentada será de acordo com a idiossincrasia de cada microconstrução, que requer um tipo de forma diferente para ter o seu pareamento próprio de forma e função.

O esquema sob análise subdivide-se em dois subesquemas, os quais abrangem as microconstruções de marcadores discursivos focalizadores com o advérbio bem, a saber: a) subesquema 1.1 - com foco em um pedido de apreciação; e b) subesquema 1.2 - com foco avaliativo-argumentativo. Na tabela abaixo, apresentamos a distribuição do esquema no que se refere ao quantitativo de marcadores discursivos pertencentes à sua hierarquia.

Tabela 3 - Distribuição quantitativa das microconstruções vinculadas ao esquema

\begin{tabular}{|c|c|c|c|c|c|}
\hline \multicolumn{6}{|c|}{ Esquema - Foco Avaliativo (bem) } \\
\hline \multicolumn{6}{|c|}{ Marcadores Discursivos } \\
\hline \multicolumn{2}{|c|}{ Ver } & \multicolumn{2}{|c|}{ Olhar } & \multicolumn{2}{|c|}{ Reparar } \\
\hline Veja bem & 9 & - & - & - & - \\
\hline Vejam bem & 7 & Olhem bem & 1 & Reparem bem & 2 \\
\hline \multicolumn{3}{|c|}{ Total de marcadores discursivos } & \multicolumn{3}{|c|}{19} \\
\hline
\end{tabular}

Na tabela acima, podemos verificar que há um total de 19 marcadores discursivos pertencentes à hierarquia do esquema, sendo, dentre estes, 16 com o verbo "ver" ( 9 referentes a "veja bem"; e 7 referentes a "vejam bem"); 1 referente ao verbo "olhar" (mas especificamente, ao marcador discursivo "olhem bem"); e 2 referentes a "reparar" (também referentes ao plural, "reparem bem"). Isto posto, nas subseções seguintes, nos ocupamos de descrever os subesquemas bem como as microconstruções pertencentes às suas hierarquias. 


\section{Os subesquemas}

$\mathrm{Na}$ análise dos dados, foram identificados dois subquemas, os quais denominamos de subesquema 1 e subesquema 2. Nesse sentido, nas seções a seguir, apresentaremos cada subesquema no que se refere à sua representação formal e à sua função e suas respectivas microconstruções.

\section{Subesquema 1 e seus respectivos padrões microconstrucionais}

O primeiro subesquema abrange as microconstruções que apresentam em comum o foco em um pedido de apreciação por parte do locutor, isto é, os marcadores discursivos pertencentes a este subesquema apresentam a característica de sequenciar um tópico (MARCUSCHI, 1989), ou seja, de iniciar um pedido de avaliação. No quadro abaixo, representamos a forma e a função deste subesquema.

\begin{tabular}{|l|l|}
\hline \multicolumn{2}{|c|}{ Subesquema 1 - Foco em um pedido de apreciação } \\
\hline Forma & $\begin{array}{l}\text { [verbo* no modo imperativo na segunda pessoa do discurso + bem + } \\
\text { (porção do discurso)] } \\
\text { *em que se encaixam apenas os verbos de percepção cognitiva, tais como } \\
\text { "olhar", "ver" e "reparar". }\end{array}$ \\
\hline Função & $\begin{array}{l}\text { Pedido de apreciação, por parte do locutor ao interlocutor, a um elemento } \\
\text { do discurso. }\end{array}$ \\
\hline
\end{tabular}

Quadro 2 - Descrição do subesquema 1 da rede construcional

A forma deste subesquema é descrita por [verbo no modo imperativo na segunda pessoa do discurso + bem + (porção do discurso)], em que, na posição de "verbo", se encaixam apenas os verbos de percepção cognitiva, tais como "olhar", "ver" e "reparar". Esses verbos podem apresentar as marcas morfológicas dos pronomes "tu", "você" e "vocês", referentes à segunda pessoa do discurso no modo imperativo. Além do verbo, a forma desse subesquema apresenta o advérbio "bem" e uma porção do discurso, a qual se trata de uma 
parte do texto em que o locutor enuncia o elemento do discurso a ser avaliado. A função deste subesquema é descrita como um pedido de apreciação, por parte do locutor ao interlocutor, em relação a um elemento do discurso. Vale destacar, nesse sentido, que a apreciação se configura como a avaliação da forma, da apresentação, da aparência e da composição de uma entidade no mundo (WHITE, 2003). Dessa forma, um locutor usa os marcadores discursivos deste subesquema a fim de que seu interlocutor aprecie um elemento do discurso da mesma maneira que ele. Isto é, há uma intenção de convencimento por parte do locutor e, nesse caso, o uso do marcador indica uma tentativa de "elucidação" da situação a partir da perspectiva do locutor.

$\mathrm{Na}$ tabela abaixo, apresentamos os dados quantitativos referentes a este subesquema, no qual podemos verificar que há, em sua hierarquia, 1 marcador discursivo "veja bem", 1 marcador discursivo "olhem bem" e 2 marcadores discursivos "reparem bem".

Tabela 4 - Distribuição quantitativa do subesquema 1 da rede construcional

\begin{tabular}{|c|r|c|c|c|c|}
\hline \multicolumn{7}{|c|}{ Subesquema 1 - Foco em um pedido de apreciação } \\
\hline \multicolumn{7}{|c|}{ Marcadores Discursivos } \\
\hline Veja bem & 1 & - & - & \multicolumn{2}{c|}{ Reparar } \\
\hline- & - & Olhem bem & 1 & Reparem bem & 2 \\
\hline
\end{tabular}

A seguir, sistematizamos, no quadro abaixo, o pareamento forma-função que caracteriza cada uma das microconstruções pertencentes à hierarquia do subesquema 1. E, subsequentemente, apresentamos e analisamos ocorrências representativas de cada padrão microconstrucional em particular.

\begin{tabular}{|l|l|}
\hline \multicolumn{2}{|c|}{ Microconstrução 1.1 - Veja bem 1 } \\
\hline Forma & $\begin{array}{l}\text { [oração avaliativa) + verbo "ver" no modo imperativo na segunda pessoa } \\
\text { do discurso + bem + (oração avaliativa) }]\end{array}$ \\
\hline Função & $\begin{array}{l}\text { Pedido de apreciação, por parte do locutor ao interlocutor, com foco a } \\
\text { uma avaliação de um elemento do discurso. }\end{array}$ \\
\hline
\end{tabular}




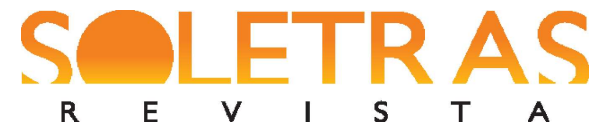

R
S T

N. 41 - 2021.1 - PATRÍCIA FABIANE AMARAL DA CUNHA LACERDA GUSTAVO RIBEIRO PATRÍCIO BARBOSA

\begin{tabular}{|l|l|}
\hline \multicolumn{2}{|c|}{ Microconstrução 1.2 - Olha bem 1 } \\
\hline Forma & $\begin{array}{l}\text { [verbo “olhar” no modo imperativo na segunda pessoa do discurso + bem } \\
+ \text { NP + (oração avaliativa) }]\end{array}$ \\
\hline Função & $\begin{array}{l}\text { Chamada de atenção a uma apreciação, por parte do locutor ao } \\
\text { interlocutor, com foco a uma avaliação de um elemento do discurso. }\end{array}$ \\
\hline \multicolumn{1}{|c|}{ Microconstrução 1.3 - Repara bem 1 } \\
\hline Forma & $\begin{array}{l}\text { [verbo "reparar" no modo imperativo na segunda pessoa do discurso + } \\
\text { bem + PP + (oração avaliativa) }]\end{array}$ \\
\hline Função & $\begin{array}{l}\text { Pedido de análise detalhada, por parte do locutor ao interlocutor, com } \\
\text { foco a uma avaliação de um elemento do discurso. }\end{array}$ \\
\hline
\end{tabular}

Quadro 3 - Pareamento forma-função das microconstruções do subesquema 1

A primeira microconstrução é descrita por: [(oração avaliativa) + verbo ver no modo imperativo na segunda pessoa do discurso + bem + (oração avaliativa)], em que "oração avaliativa" representa orações que apresentam conteúdo avaliativo, seja explícito ou não, por meio do uso de adjetivos, construções avaliativas ("eu acho que”, por exemplo) ou ainda sintagmas nominais com valor avaliativo. A representação entre parênteses significa que essas orações podem ocorrer explícitas ou implícitas e que o marcador discursivo "veja bem" ocorre de forma parentética, ou seja, pode ocorrer no início, no meio ou no final do discurso. A sua função é descrita como um pedido de apreciação, por parte do locutor ao interlocutor, com foco na avaliação de um elemento do discurso. Ou seja, o locutor pede que seu interlocutor examine um elemento do discurso conforme a avaliação apresentada. $\mathrm{O}$ foco do marcador incide sobre a avaliação, ainda que esta esteja implícita, já que a intenção do locutor é convencer seu interlocutor de sua posição. Abaixo, apresentamos uma ocorrência extraída do corpus analisado a fim de ilustrar esta microconstrução:

(3) "Essa sou com muitas lindas sacolas no dia em que fui pela primeira vez na Sephora (era no começo da viagem). Mas só uma sacola é de lá, vejam bem!" (Corpus escrito blogs).

Neste exemplo, a locutora relata um episódio em que participou de um desfile de uma marca e, logo depois, saiu às compras em uma loja de uma marca famosa. A locutora apresenta uma imagem em que ela aparece segurando algumas sacolas e avalia-as como lindas. O marcador ocorre neste exemplo de modo a focalizar esta avaliação, destacando 


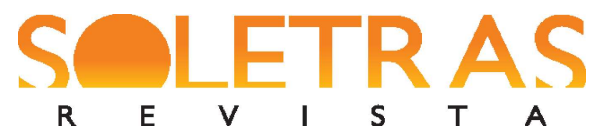

$\begin{array}{lllllllll}\mathbf{R} & \mathbf{E} & \mathbf{V} & \mathbf{I} & \mathbf{S} & \mathbf{T} & \mathbf{A} & \mathrm{N} .41-2021.1 \text { - PATRÍCIA FABIANE AMARAL DA CUNHA LACERDA }\end{array}$

GUSTAVO RIBEIRO PATRÍCIO BARBOSA

também o fato de que apenas uma dessas sacolas é dessa loja famosa. Nesta oração, a locutora apresenta uma avaliação implícita, pois deseja que seu interlocutor aprecie a sacola dessa loja específica da mesma maneira que ela, julgando-a como linda e, talvez, como uma loja que venda produtos caros.

Já a segunda microconstrução do Subesquema 1 apresenta a seguine forma: [verbo "olhar" no modo imperativo na segunda pessoa do discurso + bem + NP], em que "olhar" pode ocorrer com as marcas morfológicas dos pronomes "tu", "você" e "vocês", referentes à segunda pessoa do discurso no modo imperativo. Esta forma compõe-se também do advérbio bem, de um sintagma nominal (NP) e de uma oração avaliativa, representada entre parênteses por ter a possibilidade de ocorrer explícita ou implícita, por meio de referência a uma avaliação do contexto do texto em que o marcador discursivo se insere. A função desta microconstrução também é descrita como uma chamada de atenção para uma apreciação, por parte do locutor ao interlocutor, com foco na avaliação de um elemento do discurso. Nesse sentido, o locutor chama a atenção de seu interlocutor em relação a uma apreciação que ele mesmo faz de um elemento do discurso, desejando que seu interlocutor tenha o mesmo tipo de avaliação. O foco avaliativo acarretado pelo advérbio bem incide sobre a avaliação da oração avaliativa, como uma forma de dizer "avalie da mesma maneira que eu avalio". A seguir, apresentamos uma ocorrência representativa deste padrão construcional:

(4) “[...] a parceria com o designer indiano manish arora resultou nessa linha wonderful, que tem disparado as embalagens mais looosho que eu conheço. tudo multi colorido... olhem bem a palette "eyes on manish", um escândalo! e conforme reza a lenda, os tons alaranjados seguem firmes \& fortes ;)". (Corpus escrito blogs).

Em (4), a locutora trata de novos produtos de maquiagem e cosméticos que uma marca lançou. Ao chamar a atenção para uma paleta de sombras, a locutora usa o marcador discursivo "olhem bem" de modo a mostrar sua avaliação acerca desse produto e também a pedir que seu interlocutor aprecie da mesma forma que ela. Para isso, o foco avaliativo gerado por bem é fundamental, pois focaliza o modo como o interlocutor deve apreciar tal elemento do discurso (a paleta de sombras para olhos).

Por sua vez, a terceira microconstrução do subesquema 1 é descrita por [verbo "reparar" no modo imperativo na segunda pessoa do discurso + bem + PP + (oração avaliativa)], em que "reparar" apresenta as marcas morfológicas dos pronomes “tu”, "você" e 


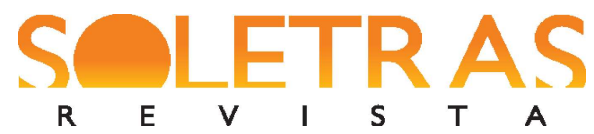

N. 41 - 2021.1 - PATRÍCIA FABIANE AMARAL DA CUNHA LACERDA GUSTAVO RIBEIRO PATRÍCIO BARBOSA

"vocês" referentes à segunda pessoa do discurso no modo imperativo. É composta também pelo advérbio bem; por um sintagma preposicional (PP), devido à regência do verbo "reparar" que pede a preposição “em”; e uma oração avaliativa, representada entre parênteses porque pode ocorrer explícita e encaixada ao PP ou coordenada, ou, ainda, pode ocorrer implícita, referenciando uma avaliação já expressa anteriormente no contexto. Descrevemos a função desta microconstrução como um pedido de análise detalhada, por parte do locutor ao interlocutor, com foco na avaliação de um elemento do discurso. Devido ao uso de "reparar", cujo sentido é "ter a atenção despertada por", esta função apresenta um caráter mais específico no pedido de análise. Dessa maneira, o locutor solicita a seu interlocutor que analise muito atentamente um elemento do discurso com base na avaliação que apresenta, de modo que a análise do interlocutor seja semelhante à do locutor. A seguir, apresentamos uma ocorrência representativa deste padrão microconstrucional:

(5) "Nem preciso repetir o tanto que gostei de estar em Fortal né? Vocês já viram e ouviram muita coisa sobre esse assunto. Mas agora, preciso dividir maissss fotos que tirei durante o bate papo! Começando pelo make up super Verão! Olha só... Reparem

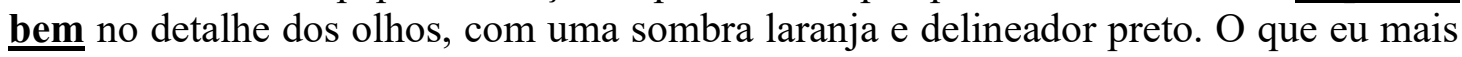
gosto dessa proposta é que, apesar da sombra ser laranja, não ficamos com cara de carnaval, sabe?". (Corpus escrito blogs).

Em (5), a locutora compartilha fotos de uma viagem realizada a Fortal durante o verão, nas quais chama a atenção acerca dos detalhes de sua maquiagem. Nesse sentido, a locutora usa o marcador discursivo de modo a pedir uma análise mais apurada de um detalhe da maquiagem; logo após, ela apresenta a sua avaliação acerca desse detalhe. Dessa maneira, o uso de bem faz com que o foco avaliativo incida sobre a maneira como o interlocutor deve, segundo a locutora, analisar a imagem apresentada por ela.

\section{Subesquema 2 e seus respectivos padrões microconstrucionais}

O segundo subesquema caracteriza-se pelo foco avaliativo-argumentativo. Nesse caso, sua característica avaliativa deve-se ao advérbio bem, ao passo que o caráter argumentativo se deve ao contexto em que se insere o marcador discursivo. Sendo assim, o contexto argumentativo é um objeto de focalização que ocorre em sequências ou textos 
argumentativos, criados a partir da argumentação instanciada pelo locutor. Nesse sentido, a argumentação é entendida como uma expressão e uma defesa de um ponto de vista elencadas de modo a sustentar uma posição que está em disputa (SCHIFFRIN, 1987). Outro aspecto deste subesquema é que, devido ao objeto de focalização ser uma sequência argumentativa, todos os verbos utilizados nos marcadores discursivos são metaforizados, isto é, não apresentam seus sentidos dicionarizados. Como os sentidos dos verbos de percepção cognitiva estão vinculados à nossa experiência de mundo, e essa experiência é percebida pelo nosso intelecto, a meteforização ocorre como um meio de transferir as informações de modo mais palatável, principalmente com os verbos de percepção visual, conforme sinaliza Sweetser (1990). Com isso, representamos, no quadro a seguir, as representações de forma e função deste subesquema.

\begin{tabular}{|l|l|}
\hline \multicolumn{2}{|c|}{ Subesquema 2 - Foco avaliativo-argumentativo } \\
\hline Forma & $\begin{array}{l}{[\text { (oração) + verbo "ver" no modo imperativo na segunda pessoa do }} \\
\text { discurso + bem + (oração) }]\end{array}$ \\
\hline Função & $\begin{array}{l}\text { Pedido de análise, por parte do locutor ao interlocutor, dos argumentos } \\
\text { apresentados no discurso sob foco avaliativo. }\end{array}$ \\
\hline
\end{tabular}

Quadro 4 - Descrição do subesquema 2 da rede construcional

A forma deste subesquema é descrita por [(oração) + verbo "ver" no modo imperativo na segunda pessoa do discurso + bem + (oração)], em que "oração" está representada entre parênteses por poder ocorrer como encaixada ou coordenada, além de ter que apresentar conteúdo argumentativo. Compõe também a forma deste subesquema o verbo "ver" no modo imperativo, apresentando as marcas morfológicas dos pronomes "você" e "vocês" referentes à segunda pessoa do discurso, e o advérbio bem, denotando foco avaliativo. Já a função deste subesquema é descrita como um pedido de análise, por parte do locutor ao interlocutor, em relação aos argumentos apresentados no discurso sob foco avaliativo. Nesse sentido, o locutor solicita ao interlocutor que faça uma análise dos argumentos apresentados, de modo a reforçar a defesa desses argumentos. O uso do advérbio bem no marcador configura foco em relação ao modo como esse argumento deve ser analisado. Assim, podemos entender que o locutor pede que o interlocutor analise este argumento sob o seu ponto de vista. Logo, os marcadores discursivos com objeto de focalização, em uma sequência argumentativa pertencente a este 
subesquema, configuram uma estratégia subjetiva de convencimento, baseada no escopo avaliativo que inclui todo o discurso, sinalizando um fenômeno subjetivo em que os argumentos têm significado cultural e podendo ser motivados para diferentes fins (VIEIRA, 2007).

$\mathrm{Na}$ tabela abaixo, mostramos o resultado quantitativo referente aos marcadores discursivos deste subesquema, os quais se referem apenas ao verbo "ver", nas formas "veja bem" -9 ocorrências - e na forma "vejam bem" -6 ocorrências. A saber:

Tabela 5 - Distribuição quantitativa do subesquema 2 da rede construcional

\begin{tabular}{|c|c|}
\hline \multicolumn{2}{|c|}{ Subesquema 2 - Foco avaliativo-argumentativo } \\
\hline \multicolumn{2}{|c|}{ Marcadores Discursivos } \\
\hline \multicolumn{2}{|c|}{ Ver } \\
\hline Veja bem & 9 \\
\hline Vejam bem & 6 \\
\hline Total: & $\mathbf{1 5}$ \\
\hline
\end{tabular}

A seguir, sistematizamos, no quadro abaixo, o pareamento forma-função que caracteriza cada uma das microconstruções pertencentes à hierarquia do subesquema 2. E, em seguida, apresentamos e analisamos ocorrências representativas de cada padrão microconstrucional em particular.

\begin{tabular}{|l|l|}
\hline \multicolumn{2}{|c|}{ Microconstrução 2.2.1 - Veja bem 2 } \\
\hline Forma & $\begin{array}{l}\text { [(porção do discurso) + verbo “ver” no modo imperativo na segunda } \\
\text { pessoa do discurso + bem + (oração argumentativa) }\end{array}$ \\
\hline Função & $\begin{array}{l}\text { Pedido de análise, por parte do locutor ao interlocutor, da informação do } \\
\text { texto anterior (anafórico) e do argumento da oração argumentativa } \\
\text { (catafórico) sob foco avaliativo. }\end{array}$ \\
\hline Forma & $\begin{array}{l}\text { Microconstrução 2.2.2 - Veja bem 3 } \\
\text { imperativo do discurso) + conjunção aditiva }+ \text { verbo "ver" no modo } \\
\text { argumentativa)] }\end{array}$ \\
\hline
\end{tabular}




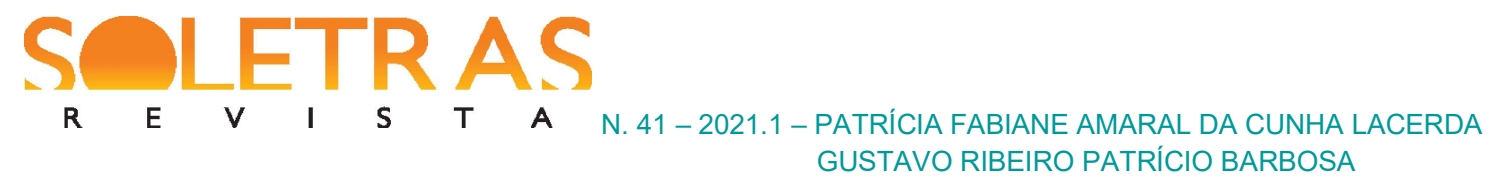

\begin{tabular}{|c|c|}
\hline Função & $\begin{array}{l}\text { Pedido de análise, por parte do locutor ao interlocutor, como foco } \\
\text { avaliativo no argumento da oração argumentativa (catafórico) em relação } \\
\text { à informação da porção do discurso (anafórico). }\end{array}$ \\
\hline \multicolumn{2}{|r|}{ Microconstrução 2.2.3 - Veja bem 4} \\
\hline Forma & {$\left[\begin{array}{l}\text { [(porção do discurso })+ \text { conjunção aditiva }+ \text { verbo "ver" no modo } \\
\text { imperativo na segunda pessoa do discurso }+ \text { bem + oração encaixada }]\end{array}\right.$} \\
\hline Função & $\begin{array}{l}\text { Pedido de análise, por parte do locutor ao interlocutor, com foco } \\
\text { avaliativo no argumento da oração encaixada (catafórico) em relação à } \\
\text { informação da porção do discurso (anafórico). }\end{array}$ \\
\hline
\end{tabular}

A primeira microconstrução é descrita por [(porção do discurso) +verbo "ver" no modo imperativo na segunda pessoa do discurso + bem+ (oração argumentativa)], em que "porção do discurso" se refere a partes do texto em que o locutor desenvolve o tema ou a tese. Por sua vez, a "oração argumentativa" representa a oração - ou orações - em que são apresentados os argumentos focalizados pelo marcador discursivo. Ambas estão representadas entre parênteses devido ao caráter parentético do marcador discursivo, que contém o verbo "ver" nas formas do modo imperativo "veja" ou "vejam" em conjunto com o advérbio bem. A sua função é descrita como um pedido de análise, por parte do locutor em relação ao interlocutor, acerca da informação do texto anterior (anafórico) e do argumento da oração argumentativa (catafórico) sob foco avaliativo. Ou seja, dentro de um contexto argumentativo em que o locutor apresenta sua tese, o uso do marcador indica um reforço de direcionamento da atenção do interlocutor em relação a um dos argumentos apresentados para sustentar a sua tese. Logo, o foco avaliativo gerado pelo advérbio bem indica a maneira como tal avaliação do argumento deve ser realizada, isto é, sob o mesmo ponto de vista do locutor. A seguir, apresentamos uma ocorrência representativa deste padrão microconstrucional:

(6) “Agora, a maquiagem tem várias graças. Uma delas é estar voltando para casa e resolver, num impulso, comprar um novo lápis azul só pra experimentar, sem que isso signifique um rombo no orçamento. Veja bem, não é pensar "ai acho que hoje quero comprar um lápis azul só para experimentar, acho que vou ao shopping procurar". (Corpus escrito blogs).

Em (6), a locutora elenca alguns dos encantos de usar e comprar maquiagem. Segundo ela, um desses encantos é comprar novos produtos apenas para teste sem que haja 


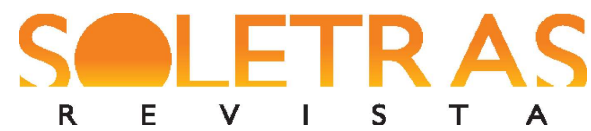

N. 41 - 2021.1 - PATRÍCIA FABIANE AMARAL DA CUNHA LACERDA GUSTAVO RIBEIRO PATRÍCIO BARBOSA

comprometimento do orçamento. Porém, a locutora argumenta - chamando a atenção para esse argumento com o marcador discursivo "veja bem" - que o encanto não é o impulso com intenção de comprar e experimentar, mas sim deparar-se com o produto e comprar porque se interessou por ele. Nesse sentido, o uso do marcador reforça o argumento da locutora e marca o seu pedido de análise para esse seu ponto de vista, focalizando-o de modo avaliativo por meio do advérbio bem. O caráter anafórico do marcador se dá pela referência à tese da locutora, ao passo que o caráter catafórico se dá pelo apontamento em relação ao argumento apresentado após o marcador discursivo.

No que se refere à segunda microconstrução do subesquema 2, sua forma é representada por [(porção do discurso) + conjunção aditiva + verbo "ver" no modo imperativo na segunda pessoa do discurso + bem + (oração argumentativa)], em que "porção do discurso" está representada entre parênteses, bem como "oração argumentativa", pois se trata de um marcador parentético. Compõem também esta microconstrução a conjunção aditiva "e", "ver" no modo imperativo, apresentando as formas "veja" ou "vejam", referentes à segunda pessoa do discurso, e o advérbio bem. A função desta microconstrução é descrita como um pedido de análise, por parte do locutor ao interlocutor, com foco avaliativo no argumento da oração argumentativa (catafórico) em relação à informação da porção do discurso (anafórico). Ou seja, o locutor solicita a seu interlocutor que analise - sob o mesmo ponto de vista - a informação do discurso e o argumento usado para sustentá-la. Desse modo, o foco avaliativo, gerado por bem, leva o interlocutor a ter o mesmo posicionamento que o locutor. Abaixo, apresentamos uma ocorrência representativa:

(7) "Sempre fui apaixonada pelo mar, minha mãe conta que era uma criança calma. Fui aquela criança que deu trabalho zero, sabe quantas vezes acordei de madrugada? NENHUMA. Sai da maternidade e já dormia a noite toda. Minha mãe acha que nasci com 'alma' velha, e veja bem, eu também acho rsrs!'. (Corpus escrito blogs).

Nesta ocorrência, a locutora relata que foi uma criança muito calma, segundo sua mãe. Devido a isso, a mãe da locutora opina que a locutora nasceu com alma de uma pessoa mais velha, e a locutora concorda com essa opinião. Desse modo, para pedir a atenção do seu interlocutor em relação a seu próprio posicionamento, a locutora usa o marcador discursivo "veja bem", que, com o foco avaliativo gerado por bem, faz com que o interlocutor reflita acerca dos pontos apresentados por ela anteriormente. E, por esse posicionamento, o 


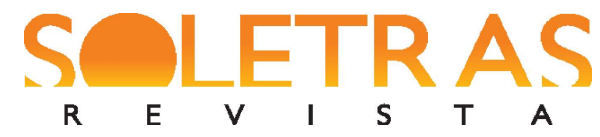

N. 41 - 2021.1 - PATRÍCIA FABIANE AMARAL DA CUNHA LACERDA GUSTAVO RIBEIRO PATRÍCIO BARBOSA

interlocutor é levado a chegar à mesma conclusão da locutora.

Por fim, a terceira microconstrução do subesquema 2 apresenta como forma [(porção do discurso) + conjunção aditiva + verbo "ver" no modo imperativo na segunda pessoa do discurso + bem+ oração encaixada], em que "porção do discurso" é entendida por parte do texto do locutor que contém o tema ou a tese defendida por ele. Além disso, também compõem esta microconstrução a conjunção aditiva "e"; o verbo "ver" no modo imperativo na segunda pessoa do discurso (apresentando as marcas morfológicas dos pronomes "você" ou "vocês"); o advérbio bem; e uma oração encaixada, na qual se apresenta o argumento da sequência argumentativa do texto. Já a sua função, descrevemos como um pedido de análise, por parte do locutor ao interlocutor, como foco avaliativo no argumento da oração encaixada (catafórico) em relação à informação da porção do discurso (anafórico). Nesse sentido, o locutor solicita ao seu interlocutor que analise - sob o mesmo ponto de vista - um argumento, apresentado em uma oração encaixada ao marcador discursivo. O foco avaliativo gerado pelo advérbio bem recai sobre o argumento da encaixada, de modo a produzir o efeito de "analise como eu analiso". A seguir, apresentamos uma ocorrência representativa deste padrão microconstrucional.

(8) Quem tem medinho pode começar com acessórios (ótemos), tipo sapato, bolsa, lenço, bracelete, broche - um desses de cada vez não escandaliza ninguém, em nenhum ambiente. E vejam bem, amigas, que a intenção não é mascarar a mensagem sexy da estampa de animal, mas acrescentar à essa outras leituras possíveis - pra gente ficar mais interessante e menos literal, no caso.". (Corpus escrito blogs).

Em (8), a locutora trata de roupas com estampas de animais, defendendo que são estampas que evidenciam a sensualidade de quem as usa, porém, para que as pessoas fujam da obviedade do conteúdo sensual que essas estampas passam, a locutora defende o uso de peças menos sensuais ou mais discretas. Ao usar o marcador discursivo, a locutora sinaliza que a intenção de usar peças menos óbvias não é mascarar a sensualidade dessas peças, mas sim causar um impacto diferente em quem vê as pessoas as usando. Desse modo, a locutora usa o marcador para focalizar seu argumento, visando a levar seu interlocutor a ter o mesmo ponto de vista que ela, o de que tais estampas podem ser usadas de maneira diferente. 


\section{Uma proposta de rede construcional}

A partir da análise realizada, em que foram apresentados os níveis esquemáticos que caracterizam os marcadores discursivos focalizadores formados por verbos de percepção cognitiva no imperativo na segunda pessoa do discurso e pelo advérbio focalizador bem no corpus analisado, apresentamos a seguinte proposta de rede construcional:

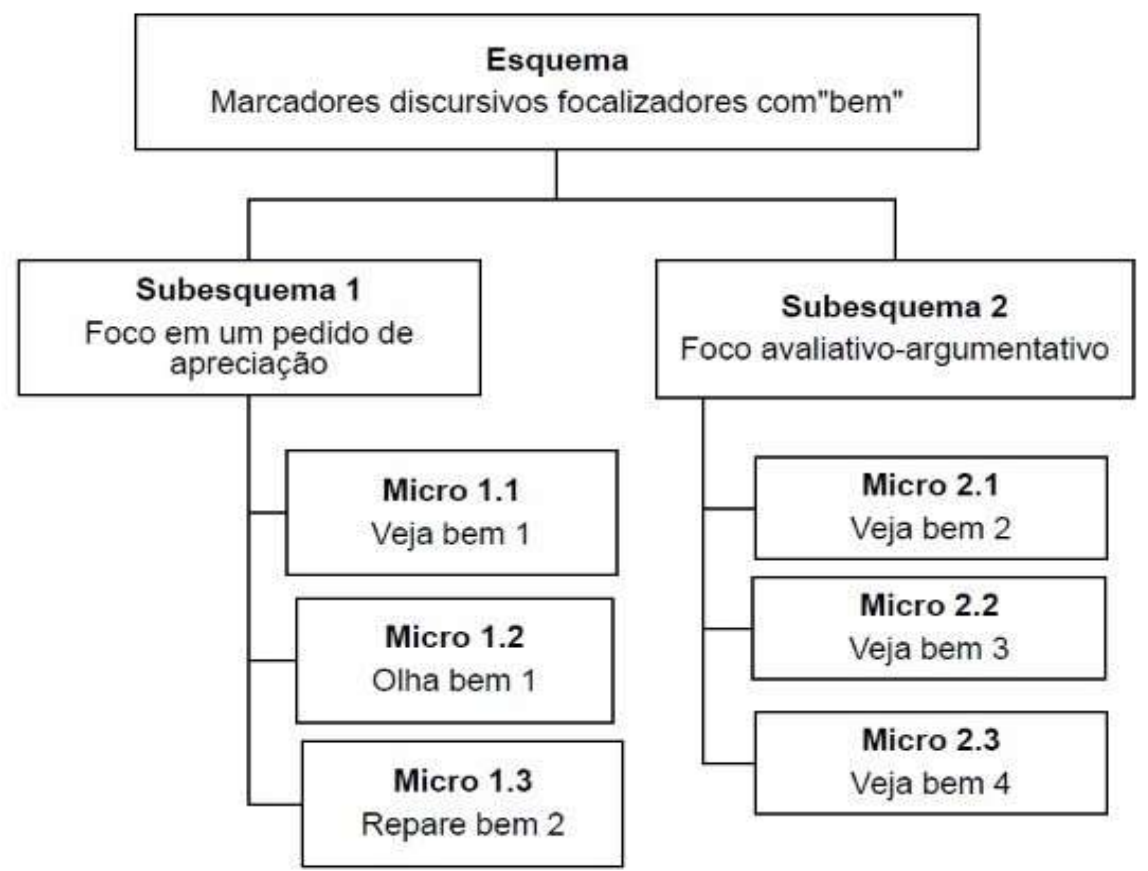

Ilustração 1 - Proposta de rede construcional

Esta proposta de rede construcional apresenta seis padrões microconstrucionais pertencentes ao esquema marcadores discursivos com função focalizadora com o advérbio bem, distribuídos em dois subesquemas. Nesse caso, os marcadores discursivos pertencentes ao esquema apresentam foco avaliativo devido ao uso do advérbio bem, e esse foco é caracterizado, conforme demonstramos, por um pedido de avaliação sob o mesmo ponto de vista do locutor.

\section{Considerações finais}

O objetivo geral deste trabalho foi propor uma rede construcional para os marcadores 


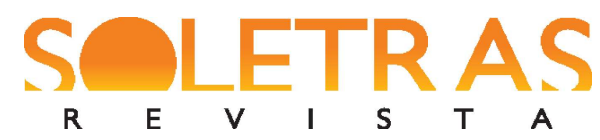

$\begin{array}{llllllll}\mathbf{R} & \mathbf{E} & \mathbf{V} & \mathbf{I} & \mathbf{S} & \mathbf{T} & \mathbf{A} & \text { N. } 41-2021.1 \text {-PATRÍCIA FABIANE AMARAL DA CUNHA LACERDA }\end{array}$

GUSTAVO RIBEIRO PATRÍCIO BARBOSA

discursivos focalizadores com bem, os quais são também formados por um verbo de percepção cognitiva no modo imperativo na segunda pessoa do discurso, como, por exemplo, "olha bem" e "veja bem". Para a realização da pesquisa, nos pautamos nos pressupostos teóricos da construcionalização gramatical, nos termos de Traugott e Trousdale (2013). De acordo com os autores, novos pares de forma e sentido passam a fazer parte da gramática da língua, estabelecendo novos nós em uma rede construcional hierarquicamente organizada.

Com base na caracterização dos padrões construcionais identificados, chegamos à conclusão de que a nossa proposta de rede é composta pelos seguintes níveis: esquema; subesquema 1 - foco em um pedido de apreciação - e suas respectivas microconstruções; e subesquema 2 - foco avaliativo-argumentativo - e suas respectivas microconstruções. Esse formato de rede foi constituído por meio de uma análise bottom-up, ou seja, para que chegássemos aos níveis mais altos da rede, partimos da análise dos construtos, separando-os por padrões microconstrucionais e agrupando-os posteriormente em subesquemas e em esquema. Nesse contexto, verificamos que a rede, então, passa a ser compreendida a partir de um continuum que vai de menos irrealis a mais irrealis, isto é, de mais factual a menos factual. Tal conclusão, pautada nos pressupostos de Palmer (1986), diz respeito às funções dos marcadores discursivos em relação a seu objeto de focalização, já que os marcadores discursivos com objeto de focalização em argumentação seriam cada vez mais irrealis, pois estariam baseados na contrafactualidade, isto é, seriam mais subjetivos em relação à realidade, já que se referem a julgamentos e pensamentos do locutor em relação a um elemento do discurso.

No que se refere à hipótese levantada no trabalho, pudemos confirmá-la a partir da análise de dados realizada. Conforme verificamos, de fato, os significados do verbo e dos advérbios concorrem para o estabelecimento da função de cada marcador discursivo em particular. E, nesse sentido, ao mesmo tempo em que cada padrão microconstrucional apresenta uma função específica e idiossincrática, há características formais e funcionais compartilhadas entre todos os marcadores discursivos, o que permite, do ponto de vista analítico, agrupá-los em subesquemas e, em um nível mais abstrato, em um esquema mais geral.

Com base nessas conclusões e em outras encaminhadas durante a realização do trabalho, acreditamos que esta pesquisa apresenta contribuições relevantes para o estudo de 


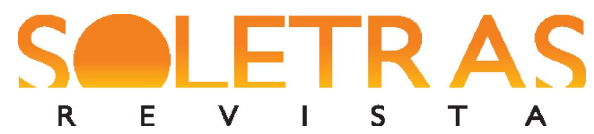

N 41 - 2021.1 - PATRÍCIA FABIANE AMARAL DA CUNHA LACERDA

GUSTAVO RIBEIRO PATRÍCIO BARBOSA

marcadores discursivos e, de modo geral, para os estudos sobre construcionalização gramatical, já que apresentamos uma proposta de rede construcional para os marcadores discursivos focalizadores com o advérbio bem identificados no corpus analisado. É nesse contexto que procuramos demonstrar que a instanciação dos marcadores discursivos focalizadores com bem está presente na sincronia atual. Entendemos, dessa maneira, que a pesquisa realizada, embora não se configure como fechada ou estanque, mostra-se relevante para os estudos que têm como alvo de investigação o uso real da língua, podendo contribuir, de algum modo, com aqueles que se dedicam à construcionalização gramatical e, de modo mais específico, aos marcadores discursivos e à noção de focalização.

\section{Referências}

BISPO, E. B.; SILVA, J. R. Variação linguística, mudança linguística e construcionalização. In: XXI SEMINÁRIO DO GRUPO DE ESTUDOS DISCURSO \& GRAMÁTICA E VIII SEMINÁRIO INTERNACIONAL DO GRUPO DE ESTUDOS DISCURSO \& GRAMÁTICA. Rio de Janeiro: UFRJ, 2016.

BRINTON, L. J. Pragmatic markers in English: Grammaticalization and discourse functions. Berlim; Nova Iorque: Mouton de Gruyter, 1996.

BYBEE, J. L. Mechanisms of change in grammaticalization: the role of frequency. In: JOSEPH, B. D.; JANDA, J. (eds.). The handbook of Historical Linguistics. Oxford: Blackwell, 2003.

Press, 2007.

Frequency of use and the organization of language. Oxford: Oxford University . Language, usage and cognition. Cambridge: Cambridge University Press, 2010.

CROFT, W. Radical construction grammar: syntactic theory in typological perspective. New York: Oxford University Press, 2001.

CROFT, W.; CRUSE, D. A. Cognitive Linguistics. Cambridge: Cambridge University Press, 2004.

CUNHA LACERDA, P. F. A. O papel do método misto na análise de processos de mudança em uma abordagem construcional: reflexões e propostas. Revista LinguíStica / Revista do 


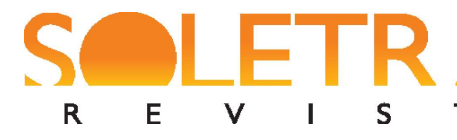

N. 41 - 2021.1 - PATRÍCIA FABIANE AMARAL DA CUNHA LACERDA GUSTAVO RIBEIRO PATRÍCIO BARBOSA

Programa de Pós-Graduação em Linguística da Universidade Federal do Rio de Janeiro. Volume Especial, p. 83-101, dez de 2016.

DIK, S. C. The theory of Functional Grammar I. Dordrecht: Foris, 1989.

FILLMORE, C. J. et al. Background to FrameNet. International Journal of Lexicography. vol.16, n.3, 2003. p. 235-250.

FURTADO DA CUNHA, M. A.; BISPO, E. B.; SILVA, J. R. Linguística funcional centrada no uso: conceitos básicos e categorias analíticas. In: CEZÁRIO, M. M.; FURTADO DA CUNHA, M. A. (orgs.). Linguística centrada no uso: uma homenagem a Mário Martelotta. Rio de Janeiro: Mauad, 2013, p. 13-44.

GOLDBERG, A. E. Constructions: a construction grammar approach to argument structure. Chicago: University of Chicago Press, 1995.

. Constructions at work: the nature of generalization in language. Oxford: Oxford University Press, 2006.

. A constructionist approach to language. Trabalho apresentado durante o XXI Seminário Nacional e VIII XXI Seminário Internacional do Grupo de Estudos Discurso \& Gramática. Rio de Janeiro: UFRJ, 2016.

LAKOFF, G.; JOHNSON, M. Metaphors We Live By. Chicago: The University of Chicago Press, 1980.

LANGACKER, R. Foundations of Cognitive Grammar, Volume 1, Theoretical Prerequisites. Stanford: Stanford University Press, 1987.

. Cognitive Grammar: A Basic Introduction. New York: Oxford University Press,

2008.

MARCUSCHI, L. A. Marcadores conversacionais do português brasileiro: formas, funções e definições. In: CASTILHO, A. (org.). Português culto falado no Brasil. Campinas: Ed. da UNICAMP, 1989. p. 281-322.

MARTElOTTA, M. E. Mudança linguística: uma abordagem baseada no uso. São Paulo: Cortez, 2011.

MARTINS DALL'ORTO, L. F. Construções avaliativas com “super”, “mega”, "hiper” e "ultra" na língua portuguesa - uma proposta de rede construcional a partir da Linguística 


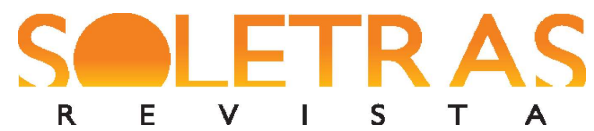

N 41 - 2021.1 - PATRÍCIA FABIANE AMARAL DA CUNHA LACERDA GUSTAVO RIBEIRO PATRÍCIO BARBOSA

Funcional Centrada no Uso. Tese de Doutorado. Juiz de Fora: Universidade Federal de Juiz de Fora, 2018.

NEVES, M. H. M. Gramática de usos do português. São Paulo: Ed. da UNESP, 2000.

OLIVEIRA, N. F. de. Gramaticalização do verbo "esperar": uma abordagem funcionalista. Dissertação de Mestrado. Universidade Federal de Juiz de Fora, Juiz de Fora, MG, 2012.

. O desenvolvimento de verbos volitivos na língua portuguesa: uma abordagem construcional. Tese de Doutorado. Universidade Federal de Juiz de Fora, Juiz de Fora, MG, 2016.

OLIVEIRA, M. R, de.; ARENA, A. B. Arquitetura constructional e competição pelo uso. In: XXI SEMINÁRIO DO GRUPO DE ESTUDOS DISCURSO \& GRAMÁTICA E VIII SEMINÁRIO INTERNACIONAL DO GRUPO DE ESTUDOS DISCURSO \& GRAMÁTICA. Rio de Janeiro: UFRJ, 2016.

PALMER, F. R. Mood and Modality. Cambridge: Cambridge University Press, 1986.

ROCHA LIMA, C. H. Gramática normativa da língua portuguesa. 53ª ed. Rio de Janeiro: José Olympio, 2017.

ROSÁRIO, I. da C. do.; OLIVEIRA, M. R. de. Funcionalismo e abordagem construcional da gramática. Alfa, São Paulo, 60 (2), p. 233-259, 2016.

ROST-SNICHELOTTO, C. A. Os marcadores discursivos nas línguas românicas: (macro) funções textuais e interacionais. Interdisciplinar: Revista de Estudos de Língua e Literatura, v. 7, 2008, p. 109/7-130.

SCHIFFRIN, D. Discourse markers. Cambridge: Cambridge University Press, 1987.

SWEETSER, E. From etymology to Pragmatics: metaphorical and cultural aspects of semantic structure. Cambridge: Cambridge University Press, 1990.

TRAUGOTT, E. C.; TROUSDALE, G. Construcionalization and Constructional changes. New York: Oxford University Press, 2013.

TRAVAGLIA, L. C. O aspecto verbal em português: a categoria e sua expressão. Uberlândia: EDUFU, 2006. 
VIEIRA, A. T. A dimensão avaliativa da argumentação na fala opinativa de profissionais de uma empresa em processo de mudança. Tese de Doutorado. Rio de Janeiro; Pontifícia Universidade Católica do Rio de Janeiro, 2007. em

WHITE, P. An introductory tour through appraisal theory. 2003. Disponível em: $<$ http:www.gramatics.com/appraisal/Appraisal Guide>. Acesso em: 10 set. 2004.

\title{
Discursive markers focalized with "bem" on a functional linguistic perspective centered in the use.
}

\begin{abstract}
This work intends to propose a constructional network constituted by discourse markers with focalizing function which are composed by cognitive perception verbs in imperative in second person of speech and by the focalizing adverb bem, for instance, "olha bem", "veja bem" and "repara bem". In order to fulfill the proposed objective, we take as theoretical approach the contributions of the Usage-Based Functional Linguistics (BYBEE, 2010; MARTELOTTA, 2011; FURTADO DA CUNHA et al., 2013; TRAUGOTT; TROUSDALE, 2013; ROSÁRIO; OLIVEIRA, 2016; BISPO; SILVA, 2016), which conceives language as an hierarchically organized inventory of constructions. Also to achieve the proposed objectives, we performed a synchronous analysis of data from a current synchronic written corpus, which its samples represent the years 2008, 2011, 2014 and 2017. In the treatment of the data, we adopted from a methodological point of view the equation between the qualitative analysis of the data and the calculation of the frequency of use (CUNHA LACERDA, 2016). As a prominent result, the analysis demonstrates that the identified constructions, in which the most generical form is [verb in imperative + bem], have different functions, highlighting among them the call for the interlocutor's attention by the speaker and the focalization of an element in the discourse sequence.
\end{abstract}

Keywords: Usage-Based Functional Linguistics. Grammatical construcionalization. Focalization. Focalizing discourse markers. Discourse markers with "bem".

Recebido em: 30 de outubro de 2020 .

Aceito em: 20 de dezembro de 2020. 